\title{
Main insights of genome wide association studies into HCV-related HCC
}

\author{
Inas Maged Moaz, Ayat Rushdy Abdallah, Marwa Fekry Yousef and Sameera Ezzat ${ }^{*}$
}

\begin{abstract}
Background: Hepatocellular carcinoma (HCC) is one of the most common causes of cancer-mortality globally. Hepatocarcinogenesis is a complex multifactorial process. Host genetic background appeared to play a crucial role in the progression of HCC among chronic hepatitis C patients, especially in the era of Genome Wide Association Studies (GWAS) which allowed us to study the association of millions of single nucleotide polymorphisms (SNPs) with different complex diseases. This article aimed to review the discovered SNPs associated with the risk of HCVrelated HCC development which was reported in the published GWA studies and subsequent validation studies and also try to explain the possible functional pathways.

Main text: We reviewed the recent GWA studies which reported several new loci associated with the risk of HCVrelated HCC, such as (SNPS) in MHC class I polypeptide-related sequence A (MICA), DEP domain-containing 5 (DEPDC5), Tolloid-like protein 1 (TLL1), and human leukocyte antigen (HLA) genes. We also explained the possible underlying biological mechanisms that affect the host immune response pathways. Additionally, we discussed the controversial results reported by the subsequent validation studies of different ethnicities.

Conclusions: Although GWA studies reported strong evidence of the association between the identified SNPs and the risk of HCV-related HCC development, more functional experiments are necessary to confirm the defined roles of these genetic mutations for the future clinical application in different populations.
\end{abstract}

Keywords: HCV, HCC, GWAS

\section{Background}

Hepatocellular carcinoma is the fifth most common cancer worldwide and the third leading cause of cancerrelated death, with a 5 -year survival rate of $6.9 \%$. The incidence of $\mathrm{HCC}$ is increasing dramatically in the last few years, the annual estimated number of HCC new cases is about 782,000 and causing 600,000 deaths annually worldwide [1].

Hepatocellular carcinoma is a multifactorial disease; host and environmental risk factors can influence its development. About $80 \%$ of $\mathrm{HCC}$ cases are caused by $\mathrm{HBV}$ and $\mathrm{HCV}$ [2].

About $7.8 \%$ of new HCC cases were attributed to HCV [3]. Recognizing patients who are more susceptible to HCC risk and following them with continuing surveillance

\footnotetext{
* Correspondence: sameera.ezzat@gmail.com

Epidemiology and Preventive Medicine Department, National Liver Institute, Menoufia University, Gamal Abdel Nasser Street, Shebein El-Kom, Menoufia, Egypt
}

for early detection and treatment will help to decrease HCC burden.

Recently, host genetics appeared to play a crucial role. Identifying host genetics would enhance the accuracy of risk prediction models, increasing the efficacy of surveillance programs, and allowing personalized assessment of disease management.

Current progress in sequencing technologies has allowed us for the identification of 500,000 or more single-nucleotide polymorphism (SNP) DNA markers selected to capture the full human genome, using genomewide association studies (GWAS) [4].

In this review, we discussed the four main genomewide association studies which investigate the association of single nucleotide polymorphisms (SNPs) with the risk of HCC development among chronic hepatitis $\mathrm{C}$ patients, the subsequent validation studies among different ethnicities and the possible underlying biological functional pathways in HCC carcinogenesis. 
Table 1 Brief summary of four main GWAS in HCV-related HCC

\begin{tabular}{|c|c|c|c|c|c|c|}
\hline Study/year & Ethnicity & Cases/controls & $\begin{array}{l}\text { Discovered } \\
\text { SNPs }\end{array}$ & Gene/Chr. & $P$ value & OR $(95 \% \mathrm{Cl})$ \\
\hline Kumar 2011 [5] & Japanese & $\begin{array}{l}\text { Discovery stage: } 721 \mathrm{HCV}-\mathrm{HCC} / 2890 \text { healthy controls } \\
\text { Replication stage: } 673 \mathrm{HCC} / 2596 \text { healthy controls }\end{array}$ & rs 2596542 & MICA/6p21.33 & $4.2 \times 10^{-13}$ & $1.39(1.27-1.52)$ \\
\hline Miki 2011 [6] & Japanese & $\begin{array}{l}\text { Discovery stage: } 212 \text { HCC-HCV/765 chronic HCV without } \\
\text { HCC } \\
\text { Replication stage: } 710 \text { HCC-HCV and } 1625 \text { chronic HCV } \\
\text { patients }\end{array}$ & rs1012068 & DEPDC5/chr. 22 & $1 \times 10^{-13}$ & $1.75(1.51-2.03)$ \\
\hline $\begin{array}{l}\text { Matsuura } \\
2017[7]\end{array}$ & Japanese & $\begin{array}{l}\text { Discovery stage: cohort group of HCV patients with } \\
\text { INF-SVR. } \\
123 \text { developed HCC/333 did not develop HCC. } \\
\text { Replication stage: } 130 \text { develop HCC/356 did not develop } \\
\text { HCC }\end{array}$ & rs17047200 & TLL1/Chr.4 & $3 \times 10^{-8}$ & $2.37(1.74-3.23)$ \\
\hline Lee 2018 [8] & Taiwan & $\begin{array}{l}\text { Discovery stage: } 502 \text { HCV-HCC/749 HCV non-HCC controls. } \\
\text { 1st replication stage: } 669 \text { HCC cases/16000 healthy controls } \\
\text { 2nd replication stage 2: } 669 \text { HCC cases/429 HCV patients }\end{array}$ & rs2856723 & HLA-DQB1/chr.6 & $2.58 \times 10^{-43}$ & $2.68(2.32-3.09)$ \\
\hline
\end{tabular}

HCV hepatitis $C$ virus, HCC hepatocellular carcinoma, INF-SVR patients received interferon and reached sustained viral response

\section{MICA (rs2596542) and HCC}

The first GWA study of HCV-related HCC was conducted by Kumar [5], and his colleagues in the Japanese population (Table 1), which was a multi-stage study. In the discovery phase, they genotyped for 432,703 SNPs in 721 HCC patients and 2890 healthy HCV-negative controls, and they identified eight possible loci for the possible association. In the replication stage, independent $673 \mathrm{HCC}$ and $2596 \mathrm{HCV}$-negative controls were genotyped at these 8 loci, One SNP rs 2596542 showed positive association in the $5^{\prime}$ flanking region of MICA on the chromosome (6p21.33), which located within the class I of the major histocompatibility complex (MHC) region (Fig. 1) [9]. Risk allele A was statistically significantly higher in HCC cases than controls $\left(P=8.62 \times 10^{-9}\right.$, odds ratio $(\mathrm{OR})=1.44$, $95 \%$ confidence interval $(\mathrm{CI})=1.27-1.63)$. The result remained significant after adjusting for age, gender, and alcohol consumption. They further analyzed for rs2596542 in 1730 chronic hepatitis $\mathrm{C}$ without cirrhosis compared with HCC cases and found it was significantly associated with progression from $\mathrm{CHC}$ to $\mathrm{HCC}(P=3.13$ $\times 10^{-8}, \mathrm{OR}=1.36$ ).

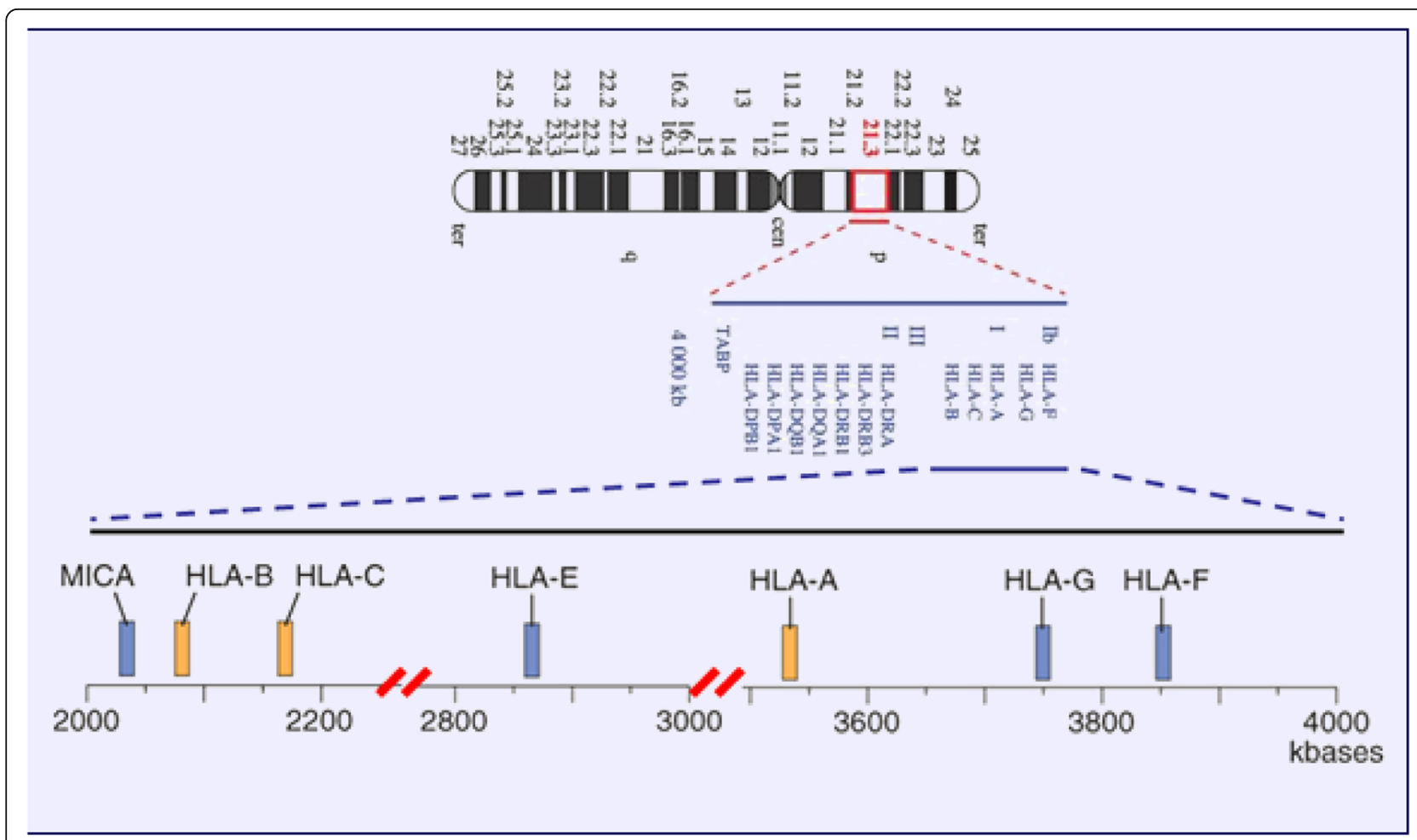

Fig. 1 The MICA gene locus on the short arm of human chromosome 6 [9] 
They also reported another locus $r s 9275572$ located between $H L A-D Q A$ and $H L A-D Q B$ which showed a significant association with $\mathrm{HCV}$-induced $\mathrm{HCC}(P=9.38 \times$ $10^{-9}$, OR $\left.=1.30\right)$, moderate association with chronic hepatitis $C$ susceptibility $(P=0.03$, OR $=1.09)$, and increased the risk of progression from $\mathrm{CHC}$ to $\mathrm{HCC}(P=$ $2.58 \times 10^{-5}$, OR $=1.29$ ).

MHC class I polypeptide-related sequence A (MICA) is a membrane protein, completely absent or present only at low levels on the surface of normal cells, but they are overexpressed by infected, transformed, senescent, and stressed cells, which play a role as a ligand for natural killer (NK) group 2D (NKG2D), that triggers natural killer cells and $\mathrm{CD} 8+\mathrm{T}$ cells to attack the target cells. Soluble MICA (sMICA) is secreted into the serum by alternative splicing, proteolytic shedding, and cause blocking the anti-tumor action of natural killer cells and CD8+ T cells.

Kumar and his team [5] identified that the rs 2596542 risk genotype AA was significantly associated with low levels of sMICA. As the levels of sMICA were shown to be correlated to the level of membrane-bound MICA which is needed for NK cell activation, they suggested that persons with rs2596542 A risk allele would show low levels of membrane-bound MICA in response to $\mathrm{HCV}$ infection, which thus leads to poor natural killer cell cytotoxicity. That can make them more susceptible to HCC progression.

\section{Validation studies for MICA and HCC (Table 2)}

The same research group conducted a replication study [10]. However, they genotyped SNP rs2596542 in 407 HBV-HCC cases, 699 CHB subjects, and 5657 non-HBV controls. SNP rs2596542 showed also a statistically significant association with HCC development in chronic hepatitis B patients. The rs2596542 G allele was more prevalent in $\mathrm{HBV}$-induced $\mathrm{HCC}$ cases than the A allele $(P=0.029, \mathrm{OR}=1.19,95 \%$ CI $1.02-1.4)$ compared to controls. The risk allele was opposite to their previous study [5] as the A allele was associated with increased risk of $\mathrm{HCV}$-related $\mathrm{HCC}$.

Similar results to Kumar GWA study [5] reported in different ethnicities, Chang and his team conducted a replication study in the Chinese population and reported a statistically significant difference in the distribution of SNP rs2596542 A allele between 120 HCC patients and 124 healthy controls $(\mathrm{OR}=1.57,95 \% \mathrm{CI}=1.07-2.31)$ [13]. An Egyptian team also reported that the rs 2596542 $\mathrm{T}$ allele was significantly higher in $\mathrm{HCC}$ versus control and liver cirrhosis (LC) versus control, suggesting that the rs2596542 $\mathrm{T}$ allele may be a risk factor for developing $\mathrm{HCC}$ and liver cirrhosis [16]. A subsequent study was conducted by Huang and his colleagues, MICA rs2596542 genotype and serum MICA (sMICA) levels were evaluated in 705 chronic hepatitis $C$ patients who received antiviral therapy and were followed up for HCC diagnosis. They reported that MICA risk alleles and high sMICA levels $>175 \mathrm{ng} / \mathrm{mL}$ were independently associated with $\mathrm{HCC}$ development in cirrhotic patients nonSVR, suggesting that combining the MICA gene polymorphism and sMICA will give the best accuracy in predicting HCC [15].

Interestingly, when replicating these studies on the Caucasian population, opposite rs2596542 A minor allele association with HCV-HCC was observed. In the study of Lange and his colleagues [12], they genotyped rs2596542 in $1860 \mathrm{HCV}$ patients and $68 \mathrm{HCV}$-related HCC patients from the European population, rs2596542 allele A was protective for HCC development which represented an opposite to the results of Kumar [5]. They

Table 2 Validation studies for association of MICA with the risk of HCC development among chronic hepatitis patients

\begin{tabular}{|c|c|c|c|c|}
\hline Study/year & Ethnicity & Cases/controls & $P$ value & OR $(95 \% \mathrm{Cl})$ \\
\hline Kumar 2012 [10] & Japanese & 407 HCC cases/699 CHB subjects and 5657 non-HBV controls & 0.029 & $1.19(1.02-1.4)$ \\
\hline Lo 2013 [11] & Japanese & 1394 HCV-HCC/1629 LC-CHC & 0.2 & - \\
\hline Lange 2013 [12] & European & 68 HCV-related HCC patients/1860 HCV patients & 0.03 & $0.58(0.35-0.95)$ \\
\hline Chang 016 [13] & Chinese & $120 \mathrm{HCC} / 124$ healthy controls & 0.02 & $1.57(1.07-2.31)$ \\
\hline Burza 2016 [14] & European & 192 LC-HCC/199 LC & 0.34 & - \\
\hline Huang 2017 [15] & Taiwanese & $\begin{array}{l}\text { Cohort of } 705 \text { patients receiving INF based antiviral } \\
\text { therapy. } \\
58 \text { develop HCC/ } 647 \text { did not develop HCC }\end{array}$ & 0.002 & $4.37(1.52-12.07)$ \\
\hline Mohamed 2017 [16] & Egyptian & 47HCV-HCC/47HCV-LC and 47 healthy controls & HCC vs. healthy 0.01 & $\begin{array}{l}\text { HCC vs. healthy } \\
2.1(1.17-3.78)\end{array}$ \\
\hline Hai 2017 [17] & Japanese & 142 HCV-HCC/575 HCV non-HCC patients & 0.0002 & $4.47(2.04-9.80)$ \\
\hline Augello 2018 [18] & Italian & 154 HCV-HCC/93 HCV-LC and 244 healthy controls & $\begin{array}{l}\text { HCC VS controls }=0.03 \\
\text { HCC VS LC }=0.04\end{array}$ & $\begin{array}{l}\text { HCC VS controls } \\
0.599(0.371-0.968) \\
\text { HCC VS LC } \\
0.522(0.276-0.989)\end{array}$ \\
\hline
\end{tabular}


suggested another novel susceptibility locus for HCVrelated HCC development rs2244546 in HCP5 which located between MICA and HLA-DQA/HLA-DQB. This was in agreement with another report from the Italian population found that homozygous AA was significantly lower frequent in $\mathrm{HCC}$ patients than in healthy controls, $\mathrm{OR}=0.599(95 \% \mathrm{CI}=0.371-0.968)$ [18].

However, Bruza and his colleagues reported in their study on population from Italy, Switzerland, and Germany that SNP s2596542 polymorphism had no statistical association with the progression of HCC in cirrhotic patients [14]. Also, Lo [11] reported after genotyping SNP rs2596542 in different groups of patients: 1043 chronic hepatitis C, 586 liver cirrhosis without HCC, and 1394 $\mathrm{HCV}$-induce $\mathrm{HCC}$ that it was significantly associated with disease progression from $\mathrm{CHC}$ to $\mathrm{LC}(\mathrm{OR}=1.17, P$ value $=0.048$ ) but was not associated with progression of $\mathrm{HCC}$ from liver cirrhosis.

\section{DEPDC5 (rs1012068) and HCC}

Another GWAS conducted in the Japanese population identified a new SNP associated with the increased risk of HCV-related HCC. The SNP rs1012068 located in the DEP domain-containing 5 genes (DEPDC5) on chromosome 22 (Fig. 2) [19]. They identified it after analyzing 467,538 SNPs in 212 chronic HCV-HCC and 765 individuals with chronic $\mathrm{HCV}$ without $\mathrm{HCC}$, followed by independent replication case-control study (710 cases and 1625 controls), $(\mathrm{rs} 1012068 \mathrm{G}, P$ combined $=1.27 \times$ $10^{-13}$, odds ratio $=1.75$ ) and the significance level of rs1012068 increased after adjusting for age, gender, and platelet count $\left(P=1.35 \times 10^{-14}, \mathrm{OR}=1.96\right)[6]$.

Further adjusting of other predictive factors of $\mathrm{HCV}$ related HCC including alcohol consumption, diabetes mellitus, obesity, ethnicity, and co-infection with HBV was performed using multiple logistic regression analysis in only 994 subjects (480 cases and 514 controls) with fully available data for these factors and rs1012068 remained highly significant with OR $=1.87(95 \% \mathrm{CI}$ 1.39-2.52). Looking for the function of DEPDC5 polymorphism, they investigated the association between rs1012068 genotype and DEPDC5 mRNA expression in
$43 \mathrm{HCV}$ patients. DEPDC5 mRNA expression was significantly higher in tumor tissues than non-tumor tissues, but no significant difference in DEPDC5 mRNA expression concerning rs1012068 genotype [6]. They recommended further research on the effect of rs1012068 polymorphism and the role of the DEPDC5 gene in HCV-related hepatocarcinogenesis.

The function of the DEPDC5 has not been defined yet; however, the protein encoded by this gene is a component of the GATOR1 (GAP activity toward Rags) complex, which has been demonstrated to act as an inhibitor of the mammalian target of rapamycin (mTOR) pathway, a multi-functional protein involved in many cellular systems including inflammation, cell growth and tumorigenesis including hepatocarcinogenesis. Most pathogenic variants described in DEPDC5 are inactivating leading to decreased amounts of the encoded protein or no protein at all, which predicted to increase the activity of the mTORC1 signaling pathway [20].

\section{Validation studies for DEPDC5 and HCC (Table 3)}

In the few past years, several studies were conducted to identify the association of the DEPDC5 gene with HCC development. Al-Qahtani and his colleagues validated the susceptible association of DEPDC5 variants with the risk of developing $\mathrm{HCC}$ in chronic $\mathrm{HCV}$-infected patients among the Saudi Arabian population [22]. They genotyped for DEPDC5 polymorphisms (rs1012068 and rs5998152) in $601 \mathrm{HCV}$ patients and 592 healthy controls. They reported that subjects carrying $\mathrm{G}$ allele of rs1012068 or C allele of rs5998152 appeared to have a higher risk for $\mathrm{HCV}$-related cirrhosis/HCC compared to $\mathrm{T}$ allele carriers of both SNPs $(P=0.038, \mathrm{OR}=1.353,95$ \% CI $=1.017-1.800)(P=0.043, \mathrm{OR}=1.342,95 \% \mathrm{CI}=$ $1.010-1.784)$, respectively.

Similar results noticed in the Han Chinese population, two separate studies postulated that The DEPDC5rs1012068 C allele was associated with increased susceptibility to HBV-related HCC $[23,24]$.

In contrast, a Japanese study tried to identify the association of MICA and DEPDC5 genetic polymorphisms with HCC recurrence following hepatectomy [21]. They

\section{Chromosome 22: $31,750,784-31,911,116$}

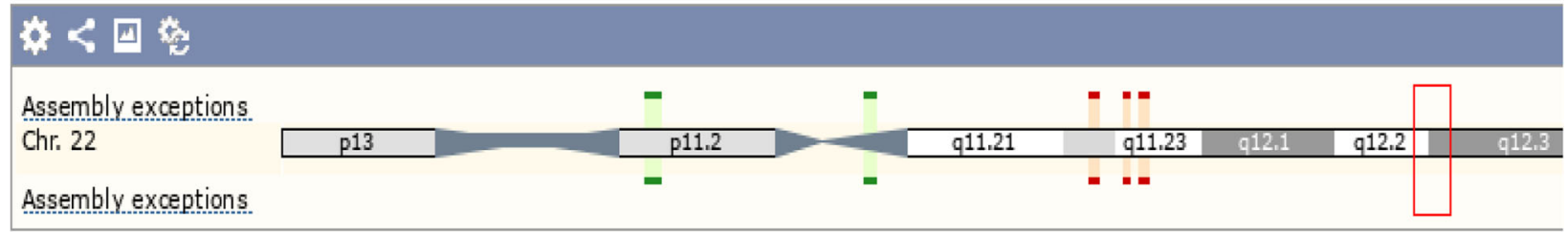

Fig. 2 The DEP domain-containing 5 genes (DEPDC5) location on chromosome 22 [19] 
Table 3 Validation studies for association of DEPDC5 with the risk of HCC development among chronic hepatitis patients

\begin{tabular}{|c|c|c|c|c|}
\hline Study/year & Ethnicity & Cases/controls & $P$ value & $\mathrm{OR}(95 \% \mathrm{Cl})$ \\
\hline $\begin{array}{l}\text { Motomura } 2012 \\
{[21]}\end{array}$ & Japanese & Cohort of 96 HCC hepatectomy patients. & 0.47 & - \\
\hline $\begin{array}{l}\text { Al-Qahtani } \\
2014 \text { [22] }\end{array}$ & Saudi & $\begin{array}{l}151 \text { cirrhotic patients + HCC patients/450 } \\
\text { Chronic HCV patients. }\end{array}$ & 0.038 & $1.353(1.017-1.80)$ \\
\hline Ma 2014 [23] & Chinese & $\begin{array}{l}308 \text { HBV-HCC/373 HBV carriers and } 111 \\
\text { cirrhotic patients }\end{array}$ & $\begin{array}{l}\text { HCC VS HBV } 0.001 \\
\text { HCC VS cirrhosis } \\
0.009\end{array}$ & $\begin{array}{l}\text { HCC VS HBV carriers } 1.549 \\
(1.207-1.988) \\
\text { HCC VS cirrhosis } 1.837 \\
(1.168-2.902)\end{array}$ \\
\hline Hai 2014 [17] & Japanese & 142 HCV-HCC/575 HCV non-HCC patients & 0.51 & - \\
\hline $\begin{array}{l}\text { Burza } 2016 \\
{[14]}\end{array}$ & $\begin{array}{l}\text { Italy, Switzerland, } \\
\text { Germany }\end{array}$ & 192 LC-HCC/199 LC & 0.15 & - \\
\hline Liu 2019 [24] & Chinese & $\begin{array}{l}308 \text { HBV-HCC patients/217 chronic HBV, } \\
258 \text { cirrhotic, and } 506 \text { healthy controls. }\end{array}$ & $\begin{array}{l}\text { HCC VS healthy } \\
\text { controls }=0.015 \\
\text { HCC VS CHB }=0.02 \\
\text { HCC VS LC }=0.004\end{array}$ & $\begin{array}{l}\text { HCC VS healthy controls } \\
2.008(1.145,3.520) \\
\text { HCC VS CHB } \\
2.241(1.226-4.461) \\
\text { HCC VS LC } \\
2.706(1.371-5.340)\end{array}$ \\
\hline
\end{tabular}

HCC hepatocellular carcinoma, $L C$ liver cirrhosis, $H C V$ hepatitis $C$ virus, $H B V$ hepatitis B virus, CHB chronic hepatitis $B$

genotyped for MICA (rs2596542) and DEPDC5 (rs1012068) and compared recurrence-free survival rates (RFS) for different genotypes in 96 HCC patients who underwent hepatectomy. They reported that neither MICA nor DEPDC5 genetic polymorphisms were associated with increased HCC recurrence risk after hepatectomy. This was consistent with another recent Japanese study that genotyped for MICA, DEPDC5, HCP5, and PNPLA3 SNPs in 717 patients with $\mathrm{CHC}(\mathrm{HCC}=142$ and non-HCC $=575$ ) [17]. These results were in line with the recent reports from Europe, which reported that the DEPDC5 variant was not associated with HCC but associated with increased fibrosis. The frequency of DEPDC5 rs1012068G was higher in cirrhotic patients (stage F4) than in those with no/mild fibrosis (stage F0F1). The DEPDC5 rs1012068 G allele was associated with a $40 \%$ increased risk of cirrhosis, OR 95\%CI (1.40: $1.08-1.81 ; P=0.011$ ) [25]. Another European study genotyped for 7 SNPs (DEPDC5 rs1012068, GRIK1 rs455804, KIF1B rs17401966, STAT4 rs7574865, MICA rs2596542, DLC1 rs2275959, and DDX18 rs2551677) in 1020 HCC, 2021 chronic liver diseases (CLD) but without HCC and 2484 healthy subjects and found also no significant association of MICA or DEPDC5 with HCC development [26]. This is indicating that the role of the DEPDC5 gene in the HCC development needs further research and validation in different ethnicities.

\section{TLL1 (rs17047200) and HCC}

Matsuura and his colleagues were interested in identifying the genetic variants associated with HCC development in HCV patients who achieved SVR after IFN-based therapy by conducting a GWA study [7]. 457 DNA samples for the discovery stage and subsequent independent 486 DNA samples for the replication stage obtained from Japanese patients who successfully achieved SVR after IFN-based therapy. The patients were followed up, and the endpoint was the HCC diagnosis date in patients who develop HCC and the date for confirming the absence of $\mathrm{HCC}$ in the last follow-up. In the discovery stage, they genotyped 123 patients who developed HCC and 333 who did not develop HCC $\geq 5$ years. The 70 SNPs which reached the GWAS level of significance further genotyped in the replication stage. Their results showed that the SNP rs17047200, located within the intron of the Tolloid-like 1 (TLL1) gene on chromosome 4 (Fig. 3) [19] had the strongest association $(\mathrm{OR}=2.35$; 95\% CI $=1.48-3.75)$ with HCC development after the eradication of HCV by IFN-based therapy. By performing Cox proportional hazard analysis, they developed a multivariate predictive model for HCC occurrence including rs17047200 AT/TT as an independent risk factor $[(\mathrm{HR})=1.78 ; 95 \% \mathrm{CI}=1.17-2.70, P=0.008]$, male gender, older age, presence of diabetes, advanced hepatic fibrosis stage, and higher post-treatment AFP level.

For evaluating the biological role of the TLL1 gene in hepatocarcinogenesis, they assessed TLL1 mRNA expression which was higher in mice models of liver injury and fibrotic human liver tissues, compared with controls. Their results were consistent with previous literature that suggested that TLL1 may be involved in carcinogenesis through activating hepatic fibrogenesis pathways by upregulation of TGF- $\beta$ signaling and subsequently activate human hepatic stellate cells (HSCs), causing excessive accumulation of the various extracellular matrix proteins in the liver [27, 28].

Cirrhosis is thought to cause initiation and promotion of neoplastic clones in regenerative nodules by facilitating genetic aberrations and cellular transformation, resulting in HCC development [29]. 


\section{Chromosome 4: 165,868,613-166,109,081}

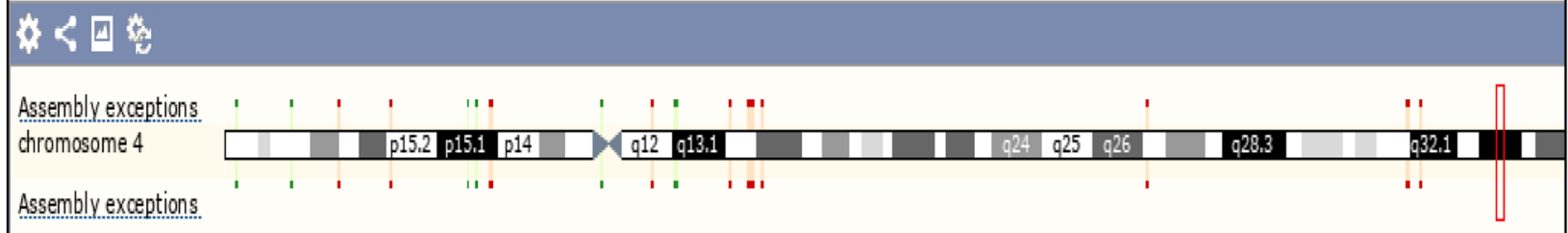

Fig. 3 The Tolloid-like 1 (TLL1) gene location on chromosome 4 [19]

Another probable explanation, suggesting that the TLL1 gene has an independent pro-oncogenic role by activating insulin-like growth factors (IGFs) through cleavage of their binding proteins and IGF signaling pathway [30]. Moreover, activation of NF-KB and ERK by activated HSC promoting HCC development [31].

\section{HLA-DQB1 (rs2856723)}

Another recent GWAS [8] genotyped 502 HCV-related HCC cases and $749 \mathrm{HCV}$ non-HCC controls, 8 SNPs showed a significant statistical association with the risk of HCC. The SNPs clustered in the human leukocyte antigen region HLA-DQB1 on chromosome 6. In the replication stage, 7 SNPs remained significantly associated with HCC, when they compared 16000 healthy controls with 669 HCC cases, and $429 \mathrm{HCV}$ patients with $669 \mathrm{HCC}$ cases. The SNP with the highest odds ratio was $r s 2856723$, OR $(95 \% \mathrm{CI})=$ 2.68 (2.32-3.09), $P=2.58 \times 10^{-43}$.

Because the HLA region is highly polymorphic, they performed a cohort study genotyping the DQB1 locus in 994 $\mathrm{HCV}$ patients and measuring the $\mathrm{HCC}$ cumulative risk among different HLA-DQB1 variants. They reported that HLA-DQB1*03:01 and DQB1*06:02 $(P<0.05)$ were statistically associated with $\mathrm{HCC}$ occurrence, and the adjusted HRs were $0.45(0.30-0.68)$ and 2.11 (1.34-3.34) for DQB1*03: 01 and DQB1*06: 02, respectively.

To identify the reported association in different $\mathrm{HCV}$ genotypes, they performed a stratified analysis by HCV genotypes, DQB1*03: 01 showed protective effects on HCC development with $\mathrm{HCV}$ genotype-1 patients; meanwhile, DQB1*06:02 increased risk of HCC only with HCV non-1 genotype patients.

The role of HLA genotypes in HCC development is not fully identified. HLA genes located on the short arm of chromosome 6 (Fig. 4) [32]; these genes encode proteins that are present on the surface of almost all cells, and their role is binding to peptides and presenting them to the immune system to be recognized as foreign to initiate a cascade of immune responses. Many studies were conducted to identify the role of HLA variants in liver disease progression, but most of them have used limited numbers of patients with a cross-sectional design and have reported inconsistent results with different ethnicities [33, 34]. This reflects the importance of providing insights into a more detailed understanding of the association of HLA polymorphism with HCC development and its functional pathway.

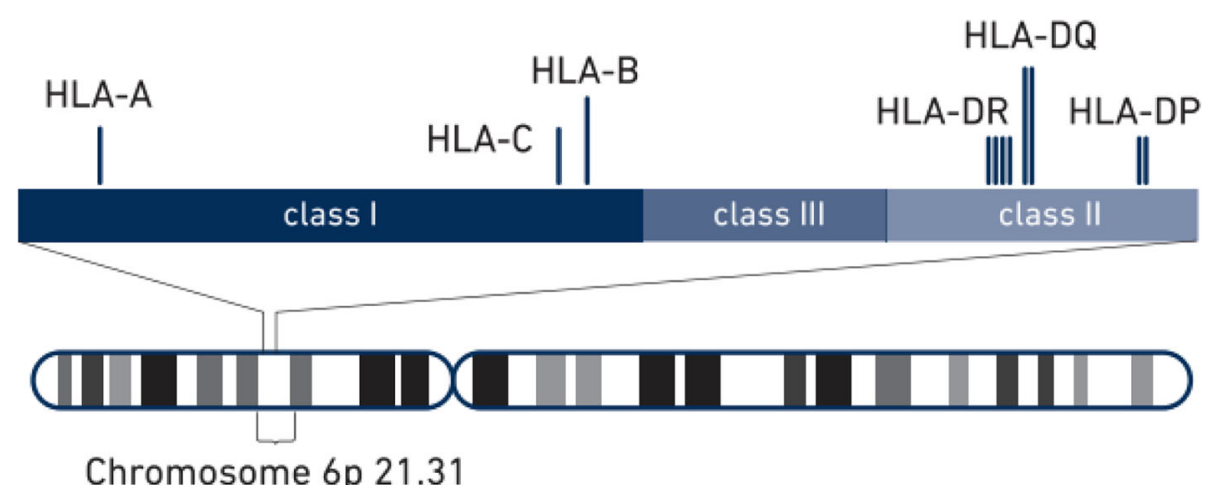

Chromosome 6p 21.31

Fig. 4 Gene map of the human leukocyte antigen (HLA) region [32] 


\section{Conclusions}

Undoubtedly, host genetic variants influence the clinical progression of $\mathrm{HCV}$ infection. In the present review, we summarized the four published genome-wide association studies of HCV-related HCC in the Asian population. Their subsequent validation studies were recruited to discuss GWAS efficiency. Most of the discovered SNPs were approved to be involved in the pathway of immune reactions. However, the identified polymorphisms need further functional analysis for their molecular role in carcinogenesis. Further GWA studies and replication studies of $\mathrm{HCV}$-related $\mathrm{HCC}$ in different ethnicities are necessary for the future as all previous published GWA studies were conducted on the Asian population. The identified polymorphisms may serve as the potential markers for screening the patients at high risk of HCC and help in modeling preventive or therapeutic strategies based on inter-individual susceptibilities, which present a great step toward personalized medicine.

\section{Abbreviations}

AFP: Alpha-fetoprotein; CHC: Chronic liver cirrhosis; DAA: Direct-acting antiviral; DEPDC5: DEP domain-containing 5; GWAS: Genome-wide association study; HBV: Hepatitis B virus; HCC: Hepatocellular carcinoma; HCV: Hepatitis C virus; HLA: Human leukocyte antigen; IFN: Interferon; IGFs: Insulin-like growth factors; LC: Liver cirrhosis; MICA: MHC class I polypeptide-related sequence A; NKG2D: Natural Killer (NK) Group 2D; SMICA: Serum MICA; SNP: Single nucleotide polymorphism; SVR: Sustained virological response; TGF- $\beta$ : Transforming growth factor beta 1; TLL1: Tolloid-like protein 1

\section{Acknowledgements}

Not applicable

\section{Authors' contributions}

IM collected, critically interprited the study data, and contributed in the manuscript writing. AA and MF contributed in the manuscript writing. SE was a major contributor to the manuscript writing and revising. All authors read and approved the final manuscript.

\section{Funding}

No fund was received for this study.

\section{Availability of data and materials}

Data materials are available under reasonable request.

\section{Ethics approval and consent to participate}

Not applicable

\section{Consent for publication}

Not applicable.

\section{Competing interests}

The authors declare that they have no competing interests.

Received: 19 September 2019 Accepted: 12 December 2019

Published online: 03 February 2020

\section{References}

1. Ozakyol A (2017) Global epidemiology of hepatocellular carcinoma (HCC epidemiology). J Gastrointest Cancer. 48(3):238-240. https://doi.org/10.1007/ s12029-017-9959-0

2. Fung J, Lai C-L, Yuen M-F (2009) Hepatitis B and C virus-related carcinogenesis. Clin Microbiol Infect. 15(11):964-970. https://doi.org/10. 1111/j.1469-0691.2009.03035.x
3. Plummer M, de Martel C, Vignat J, Ferlay J, Bray F, Franceschi S (2016) Global burden of cancers attributable to infections in 2012: a synthetic analysis. Lancet Glob Heal. 4(9):e609-e616. https://doi.org/10.1016/\$2214109X(16)30143-7

4. O'Brien TR, Yang HI, Groover S, Jeng WJ (2019) Genetic factors that affect spontaneous clearance of hepatitis C or B virus, response to treatment, and disease progression. Gastroenterology. 156(2):400-417. https://doi.org/10. 1053/j.gastro.2018.09.052

5. Kumar V, Kato N, Urabe $Y$ et al (2011) Genome-wide association study identifies a susceptibility locus for HCV-induced hepatocellular carcinoma. Nat Genet. 43(5):455-458. https://doi.org/10.1038/ng.809

6. Miki D, Ochi H, Hayes CN et al (2011) Variation in the DEPDC5 locus is associated with progression to hepatocellular carcinoma in chronic hepatitis C virus carriers. Nat Genet. 43(8):797-800. https://doi.org/10.1038/ng.876

7. Matsuura K, Sawai H, Ikeo K et al (2017) Genome-wide association study identifies TLL1 variant associated with development of hepatocellular carcinoma after eradication of hepatitis C virus infection. Gastroenterology. 152(6):1383-1394. https://doi.org/10.1053/j.gastro.2017.01.041

8. Lee $\mathrm{M}-\mathrm{H}$, Huang $\mathrm{Y}-\mathrm{H}$, Chen $\mathrm{H}-\mathrm{Y}$ et al (2018) Human leukocyte antigen variants and risk of hepatocellular carcinoma modified by hepatitis $C$ virus genotypes: a genome-wide association study. Hepatology. 67(2):651-661. https://doi.org/10.1002/hep.29531

9. Mizuki N, Ando H, Kimura M et al (1997) Nucleotide sequence analysis of the HLA class I region spanning the 237-kb segment around the HLA-B and -C genes. Genomics. 42(1):55-66. https://doi.org/10.1006/geno.1997.4708

10. Kumar V, Matsuda K, Kato N et al (2012) Soluble MICA and a MICA Variation as Possible Prognostic Biomarkers for HBV-Induced Hepatocellular Carcinoma. PLoS One. 7(9):e44743. https://doi.org/10.1371/journal.pone. 0044743

11. Lo PHY, Kumar V, Kubo M et al (2013) Identification of a functional variant in the MICA promoter which regulates MICA expression and increases HCVrelated hepatocellular carcinoma risk. PLoS One. 8(4):e61279. https://doi.org/ 10.1371/journal.pone.0061279

12. Lange CM, Bibert S, Dufour JF et al (2013) Comparative genetic analyses point to HCP5 as susceptibility locus for HCV-associated hepatocellular carcinoma. J Hepatol. 59(3):504-509. https://doi.org/10.1016/j.jhep.2013.04.032

13. Chang $H$, Zhou $X$, Zhu $H$, et al. Interaction between polymorphisms of IFN- $\gamma$ and MICA correlated with hepatocellular carcinoma. Med Sciefile///C/Users/ user/Documents/review/CH2/2018_Book_GeneticEpidemiology.pdfnce Monit. 2016;22:549-553. doi: https://doi.org/10.12659/msm.895101

14. Burza MA, Motta BM, Mancina RM et al (2016) DEPDC5 variants increase fibrosis progression in Europeans with chronic hepatitis $C$ virus infection. Hepatology. 63(2):418-427. https://doi.org/10.1002/hep.28322

15. Huang C, Huang C, Yeh M et al (2017) EBioMedicine genetics variants and serum levels of $\mathrm{MHC}$ class I chain-related $\mathrm{A}$ in predicting hepatocellular carcinoma development in chronic hepatitis C patients post antiviral treatment. EBIOM. 15:81-89. https://doi.org/10.1016/j.ebiom.2016.11.031

16. Mohamed AA, Elsaid OM, Amer EA et al (2017) Clinical significance of SNP (rs2596542) in histocompatibility complex class I-related gene A promoter region among hepatitis $C$ virus related hepatocellular carcinoma cases. J Adv Res. 8(4):343-349. https://doi.org/10.1016/j.jare.2017.03.004

17. Hai H, Tamori A, Thuy LTT et al (2017) Polymorphisms in MICA, but not in DEPDC5, HCP5 or PNPLA3, are associated with chronic hepatitis C-related hepatocellular carcinoma. Sci Rep. 7(1):11912. https://doi.org/10.1038/ s41598-017-10363-5

18. Augello G, Cervello M, Balasus D et al (2018) Association between MICA gene variants and the risk of hepatitis $C$ virus-induced hepatocellular cancer in a Sicilian Population Sample. Omi A J Integr Biol. 22(4):274-282. https:// doi.org/10.1089/omi.2017.0215

19. Zerbino DR, Achuthan $P$, Akanni W et al (2018) Ensembl 2018. Nucleic Acids Res. 46(D1):D754-D761. https://doi.org/10.1093/nar/gkx1098

20. Bar-Peled L, Chantranupong L, Cherniack AD et al (2013) A tumor suppressor complex with GAP activity for the Rag GTPases that signal amino acid sufficiency to mTORC1. Science (80- ) 340(6136):1100-1106. https://doi.org/10.1126/science.1232044

21. Motomura T, Ono Y, Shirabe K et al (2012) Neither MICA Nor DEPDC5 Genetic polymorphisms correlate with hepatocellular carcinoma recurrence following hepatectomy. HPB Surg 2012:1-6. https://doi.org/10.1155/2012/185496

22. Al-Qahtani AA, Al-Anazi MR, Matou-Nasri S et al (2014) Variations in DEPDC5 gene and its association with chronic hepatitis C virus infection in Saudi Arabia. BMC Infect Dis. 14(1):632. https://doi.org/10.1186/s12879-014-0632-y 
23. Ma N, Zhang X, Yu F et al (2014) Role of IFN- $\lambda$ s, IFN- $\lambda$ s related genes and the DEPDC5 gene in hepatitis B virus-related liver disease. J Viral Hepat. 21(7):e29-e38. https://doi.org/10.1111/jvh.12235

24. Liu W, Ma N, Zhao D et al (2019) Correlation between the DEPDC5 rs1012068 polymorphism and the risk of HBV-related hepatocellular carcinoma. Clin Res Hepatol Gastroenterol. https://doi.org/10.1016/j.clinre. 2018.12.005

25. Mancina RM, Fargion S, Stickel F et al (2015) DEPDC5 variants increase fibrosis progression in Europeans with chronic hepatitis $\mathrm{C}$ virus infection. Hepatology. 63(2):418-427. https://doi.org/10.1002/hep.28322

26. Yang J, Trépo E, Nahon P et al (2019) PNPLA3 and TM6SF2 variants as risk factors of hepatocellular carcinoma across various etiologies and severity of underlying liver diseases. Int J Cancer. 144(3):533-544. https://doi.org/10. 1002/ijc.31910

27. Ge G, Greenspan DS (2006) BMP1 controls TGF $\beta 1$ activation via cleavage of latent TGF $\beta$-binding protein. J Cell Biol. 175(1):111-120. https://doi.org/10. 1083/jcb.200606058

28. BENYON RC (2000) Is liver fibrosis reversible? Gut. 46(4):443-446. https://doi. org/10.1136/gut.46.4.443

29. Aihara T, Noguchi S, Sasaki Y, Nakano H, Imaoka S (1994) Clonal analysis of regenerative nodules in hepatitis $\mathrm{C}$ virus-induced liver cirrhosis. Gastroenterology. 107(6):1805-1811 http://www.ncbi.nlm.nih.gov/pubmed/ 7958695

30. Nalesnik MA, Michalopoulos GK (2012) Growth factor pathways in development and progression of hepatocellular carcinoma. Front Biosci (Schol Ed) 4:1487-1515 http://www.ncbi.nlm.nih.gov/pubmed/22652888

31. Amann T, Bataille F, Spruss T et al (2009) Activated hepatic stellate cells promote tumorigenicity of hepatocellular carcinoma. Cancer Sci. 100(4):646653. https://doi.org/10.1111/j.1349-7006.2009.01087.x

32. Berlingerio M, Bonchi F, Curcio M, Giannotti F, Turini F. Mining clinical, immunological, and genetic data of solid organ transplantation. In: ; 2009: 211-236. doi: https://doi.org/10.1007/978-3-642-02193-0_9

33. Duggal P, Thio CL, Wojcik GL et al (2013) Genome-wide association study of spontaneous resolution of hepatitis $C$ virus infection: data from multiple cohorts. Ann Intern Med. 158(4):235. https://doi.org/10.7326/0003-4819-1584-201302190-00003

34. López-Vázquez A, Rodrigo L, Miña-Blanco A et al (2004) Extended human leukocyte antigen haplotype EH18.1 influences progression to hepatocellular carcinoma in patients with hepatitis C virus infection. J Infect Dis. 189(6):957-963. https://doi.org/10.1086/382189

\section{Publisher's Note}

Springer Nature remains neutral with regard to jurisdictional claims in published maps and institutional affiliations.

\section{Submit your manuscript to a SpringerOpen ${ }^{\circ}$ journal and benefit from:}

- Convenient online submission

- Rigorous peer review

- Open access: articles freely available online

- High visibility within the field

- Retaining the copyright to your article

Submit your next manuscript at $\boldsymbol{\nabla}$ springeropen.com 